\title{
Ovarian Seromucinous Carcinoma
}

National Cancer Institute

\section{Source}

National Cancer Institute. Ovarian Seromucinous Carcinoma. NCI Thesaurus. Code C40090.

A malignant mixed epithelial neoplasm that arises from the ovary and is composed predominantly of serous and endocervical-type mucinous epithelium. 